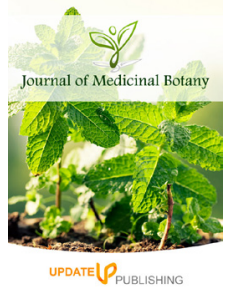

ISSN: $2521-3903$
Received: March 17, 2020 Accepted: May 31, 2020 Published: June 20, 2020

*Corresponding Author: Hamdi Bendif

E-mail: hamdi.bendif@ univ-msila.dz

\section{Ethnobotanical study of the toxicity of Ecballium elaterium (L.) A. Rich. in the Northeast of Algeria}

\author{
Nabila Souilah', Rym Amrouni², Hamdi Bendif3*, Nassera Daoud4, \\ Hacene Laredj 5
}

'Department of Natural Sciences and Life, Faculty of Science, University of Skikda, 21000 Algeria, ${ }^{2}$ Department of Pharmacy, Faculty of Medicine, University of Constantine 3, Algeria, ${ }^{3}$ Natural Sciences and Life Department, Faculty of Sciences, University of M'sila, P.B. 166 M'sila 28000, M'sila, Algeria, ${ }^{4}$ Department of Biology, Faculty of Natural and Life Sciences, University of Ziane Achour, Djelfa, Algeria, ${ }^{5}$ Department of Pharmacy, Faculty of Medicine, University of Annaba, Algeria

\begin{abstract}
Medicinal plants still remain a source of medical care in developing countries, in the absence of a modern medical system. The use of herbal medicine is deeply rooted in our culture, because Algeria is renowned for the richness of its medicinal flora which includes hundreds of plant species. Ecballium elaterium (L.) A. Rich. the species reported in this study is traditionally used in Algeria for a wide range of illnesses. The aim of this study was to evaluate the potential toxicity of it. Many herbalists (two hundred) in different regions in Northern Algeria (Tébessa, Khenchela, Oum El Bouaghi, Constantine, Skikda) were questioned to recognize the toxicological concern of E. elaterium in Algerian traditional medicine in these regions.
\end{abstract}

KEYWORDS: Ethnobotany, Medicinal plants, Northeast of Algeria, Toxicity

\section{INTRODUCTION}

The plant Ecballium elaterium (E. elaterium) is commonly called squirting cucumber in English, spritzgurke in German, and concombre sauvage in French and was known to the ancient Greeks, having been described by the Greek philosopher Theophrastus in his history of plants [1]. E. elaterium is the scientific name of a plant belonging to Cucurbitaceae family. The plant is a decumbent, perennial herb (Figure 1); it is a wild medicinal plant indigenous and found abundantly in the Mediterranean region, and cultivated in central Europe and England. The fruit of this species is ovoid, fleshy; approximately $4 \mathrm{~cm}$ in length, when unripe of a pale green color, and covered with numerous, uniseriate glandular hairs [2]. The interior of the fruits contains black seeds and a liquid known as 'juice of E. elaterium'. The juice contains proteins, lipids, and sugars [3]. In folk medicine, E. elaterium, was empirically used as a purgative, because it is an energetic hydragogue cathartic, operating with great violence in doses of a few grams. Because of its property of producing copious watery evacuation from the mucosa and the vessels, it has been also used in the treatment of pulmonary edema and ascites, and to control arterial hypertension. E. elaterium is of interest today because its fruits extracts are still used in Mediterranean region in different medicinal system [4,5]. Whose fruit juice is used for the treatment of jaundice, also is widely used, by people in the eastern Mediterranean region, to treat sinusitis, because of its inherent anti-inflammatory properties. However, the use of E. elaterium in some allergy-prone patients causes adverse reactions, such as edema of the upper respiratory tract, resulting in an emergency situation, which the otolaryngologist is frequently asked to diagnose and treat $[2,4]$. The fresh crude juice frequently used in the treatment of irritation of mucous membranes, drooling, dysphagia, and vomiting [6]. The diluted aqueous extract of E. elaterium fruits is a traditional anti-inflammatory and analgesic for chronic sinusitis. It also possesses other uses especially the treatment of fever, cancer, liver disorders, jaundice, constipation, hypertension, dropsy, rheumatic diseases, and fungicidal $[7,8,9]$. Man recognized very early the toxicity of plants, very early on, he also recorded his observation but if learning by trial and error of immediate toxicity and optimal quantities to be used was within reach of past centuries, the manifestations induced by therapy long term and especially the notion of adverse effects could not escape the best of observations. These effects can only be suspected by the accumulation of observations and experimentation and-if

Copyright: $\odot$ The authors. This article is open access and licensed under the terms of the Creative Commons Attribution License (http://creativecommons.org/licenses/by/4.0/) which permits unrestricted, use, distribution and reproduction in any medium, or format for any purpose, even commercially provided the work is properly cited. Attribution - You must give appropriate credit, provide a link to the license, and indicate if changes were made. 
necessary - they are confirmed by ethnobotanical studies. This ethnobotanical survey was conducted in order to highlight the importance and uses of a plant of toxicological concern $(\mathrm{E}$. elaterium) in traditional medicine. The choice of this plant for the practical study was based on its wide distribution in the Algerian territory, and its use for different indications and ignoring its real dangers to the patient's health because its toxicity is not too studied as other plants.

\section{MATERIALS AND METHODS}

\section{The Study Area, Ethnobotanical Survey and Data Collection}

During the period of February-October 2018, field work investigation was done to lay down a comprehensive survey study about the toxicity of E. elaterium (Figure 1); the data regarding the use of this plant were collected from 200 herbalist's

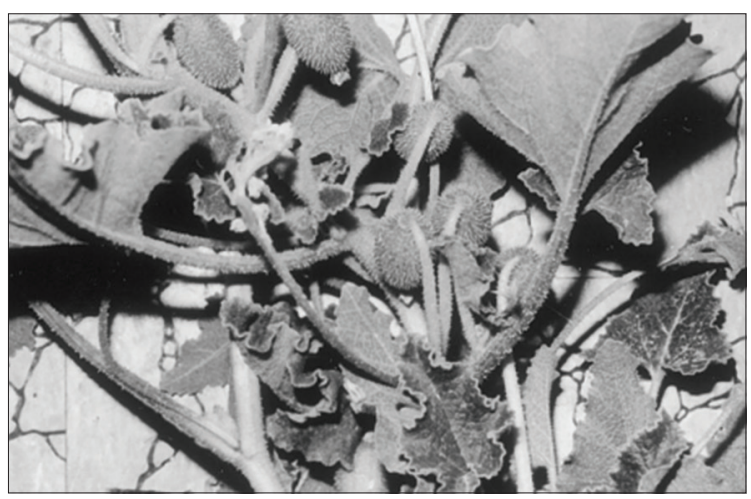

Figure 1: The plant Ecballium elaterium (squirting cucumber) exercisers and experienced in the different provinces following: Skikda (40 survey), Constantine (40 survey), Oum El Bouaghi (40 survey), Khenchela (40 survey) and Tébessa (40 survey) (Figure 2). Most of the herbalist's were either native born or had been living in the area for long time. The study areas were chosen according to an increasing aridity gradient, from the humid sub which is in the northeast, as is the case of Skikda, which is considered as the wettest region in Algeria to the arid as Tebessa.

\section{RESULTS AND DISCUSSION}

The questioned herbalists are of opposite sex: $86 \%$ men and $14 \%$ women (Figure 3). $48 \%$ of them in this trade for over 20 years, or 60 years, $30 \%$ exercise only for 10 years, the rest $(22 \%)$ are in this business for 10-20 years (Figure 4).

It was found that the majority of herbalists $(80 \%)$ have learned these traditional medical knowledges through experience and practice. Only 20\% are university graduates, particularly in biology and botany (Figure 5). These herbalists practice their craft in the popular souks (52\%) and in stores (40\%). Only 8\% of them work at home (female) (Figure 6).

As regards the plant, all the herbalists know. $74 \%$ the mean by its vernacular name "fagouss lahmir" and 26\% also know it by other names, especially "fagouss aghyoul" or "fagouss boughyoul" (Figure 7).

This herb is prescribed in its fresh form only, $72 \%$ of herbalists, its form desiccated by only $4 \%$. All these herbalists claim that all parts of the plants, only the fruit is used (Figure 8).

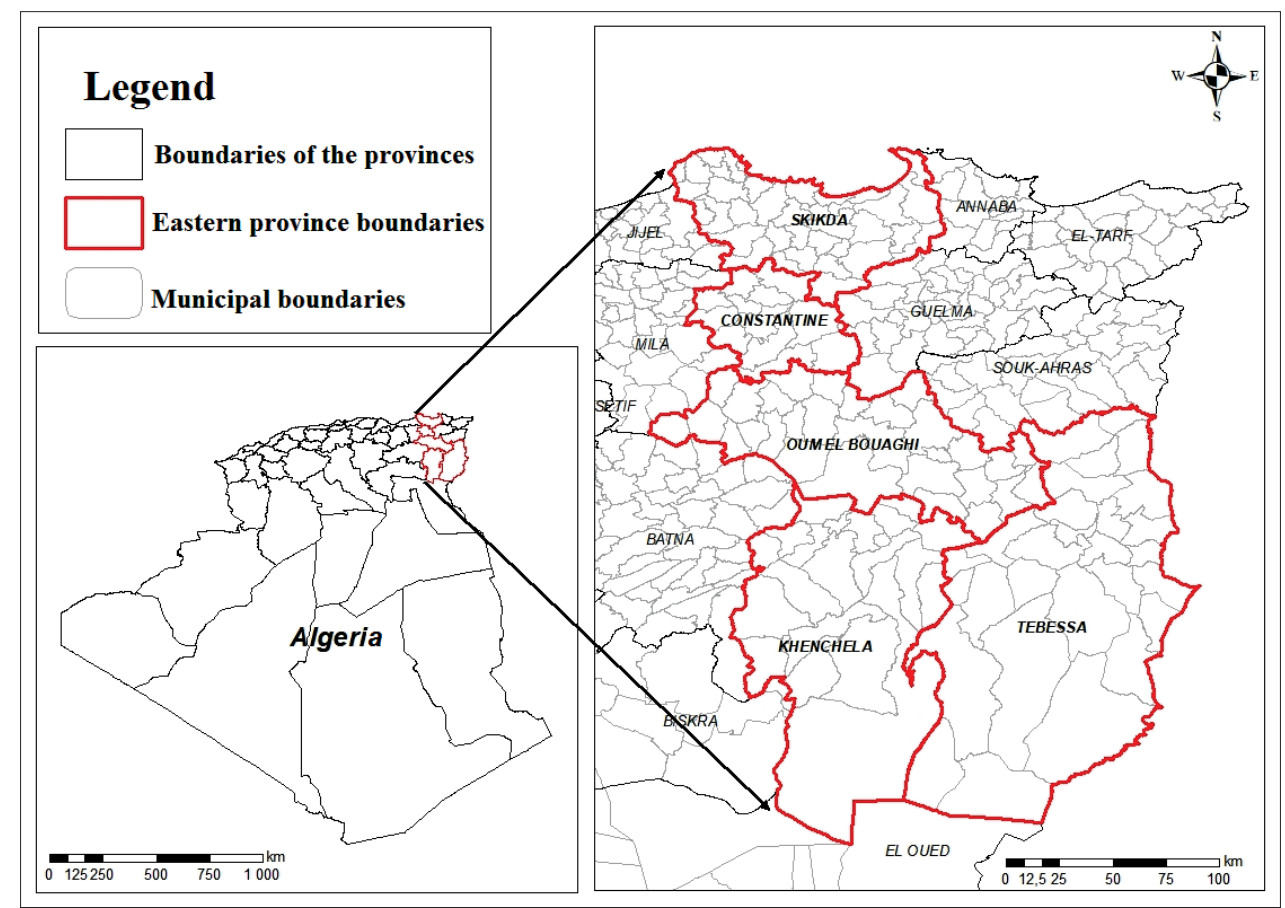

Figure 2: Map of the regions considered in this study (Northernest of Algeria: Skikda Constantine Oum Bouaghi Khenchela Tébessa) 
The fruit is given only by $70 \%$ of herbalists, while $30 \%$ give it in combination with olive oil above (and also with: gourd, turmeric, henna, clove, cinnamon, garden cress, cypress, mastic, lemon, honey, raw eggs, goat milk, goat meat and fat, vegetable fat and even lentil soup) (Figure 9).

The fruit is recommended for patients with jaundice and hepatitis by $44 \%$ of herbalists, and treating hemorrhoids (16\%), headache $(16 \%)$, diabetes (12\%) and constipation (10\%). The fruit is also used for the treatment of other ailments such joint and rheumatic pain, fever and ear infections; and for cosmetic purposes (strengthen hair) (Figure 10)

Other uses of this plant were for the treatment of acute or chronic sinusitis, and to treat chronic rhinitis, although the use

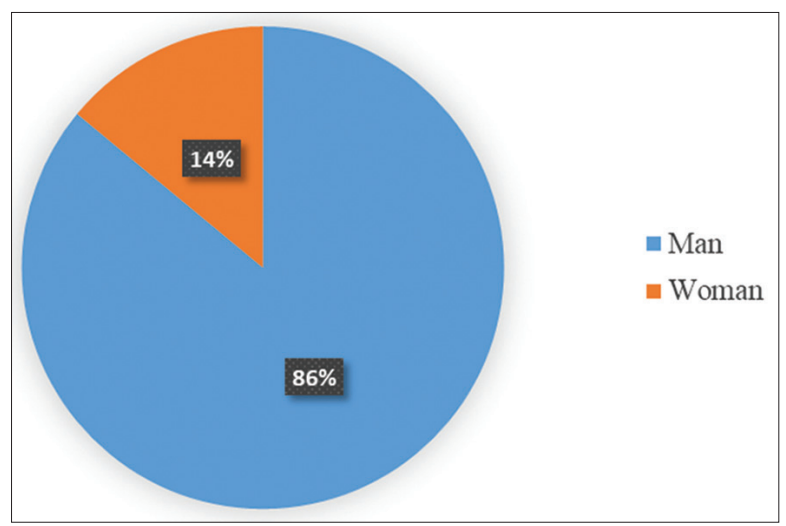

Figure 3: Distribution of herbalist's sex

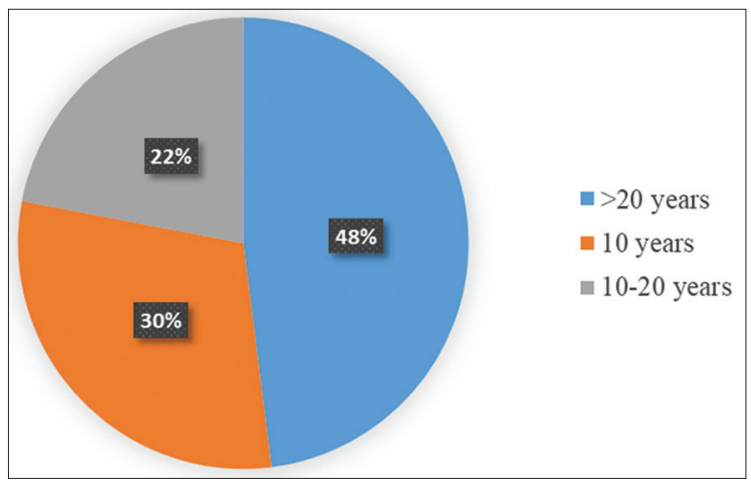

Figure 4: Distribution of herbalists on the accrual period

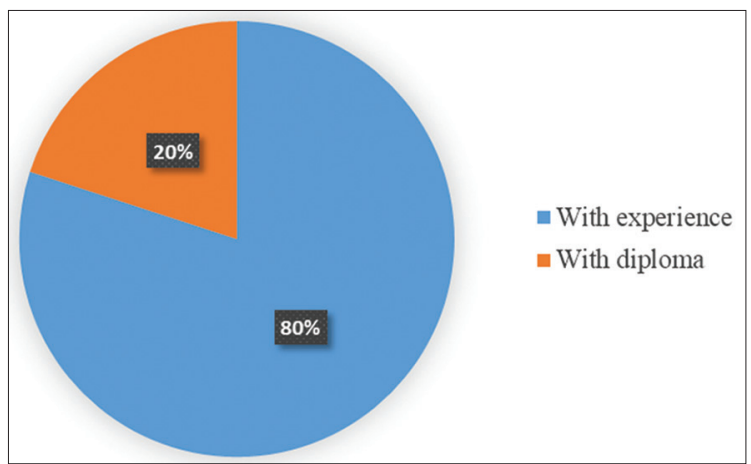

Figure 5: Distribution of herbalists according to their level of study of Ecballium elaterium in treating rhinologic diseases is known to many otolaryngologists of the Mediterranean region, It seems that the juice of the fruit of E. elaterium indeed possesses curative properties for treating sinusitis and rhinitis, However, in a small number of allergy-prone persons, the fruit juice of E. elaterium causes allergic edema, which is located usually at the uvula or involves the nasal mucosa. In a few cases swelling occurs in other sites such as the lips, the tongue, or even at multiple sites, in a few patients the action of E. elaterium may be attributed to the contact of a large quantity of the fruit juice to the mucosa of the oral and the nasal cavity [2].

As for the route of administration, $70 \%$ of herbalists have agreed on the nasal instillation knew fruit juice, making the major route of traditional use, followed by maceration of the

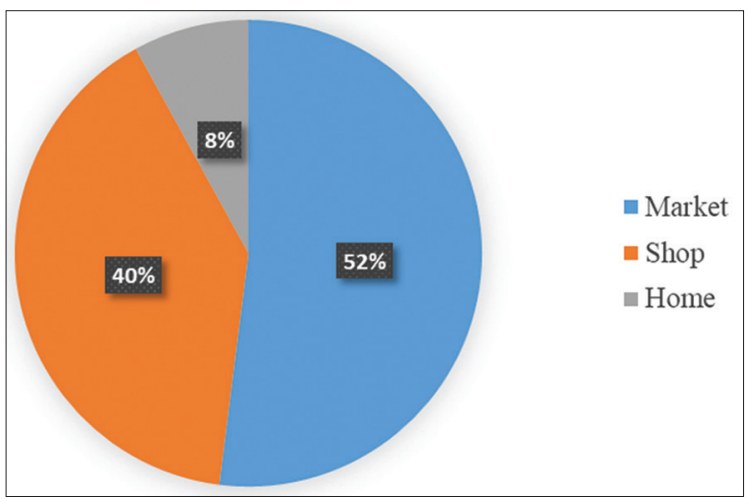

Figure 6: Distribution of herbalists by place of exercise

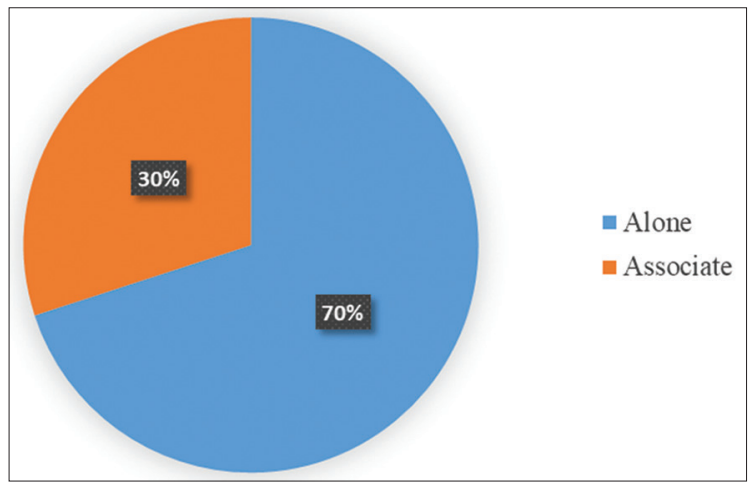

Figure 7: Use of Ecballium elaterium methods

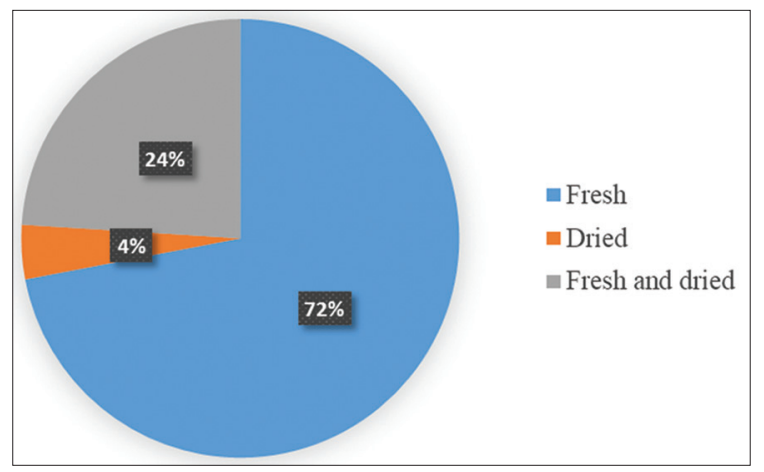

Figure 8: Use forms of Ecballium elaterium 
dry fruit $(26 \%)$. The other routes (rectal, oral and external use) are in the minority and are prescribed by $12 \%, 8 \%, 4 \%$ herbalists (Figure 11).

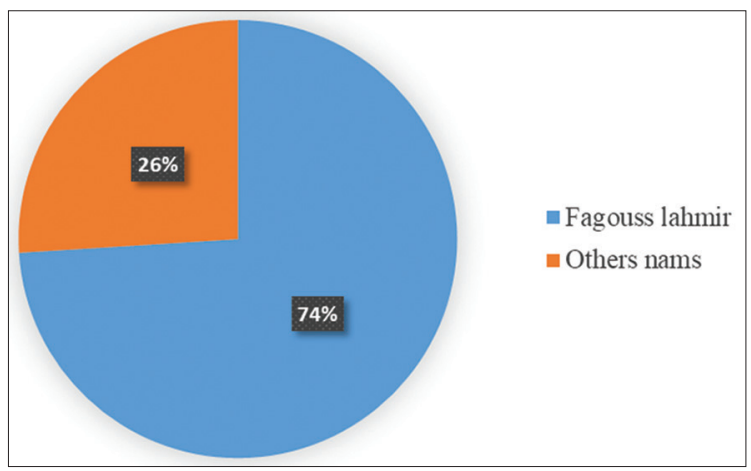

Figure 9: Known appellations plant

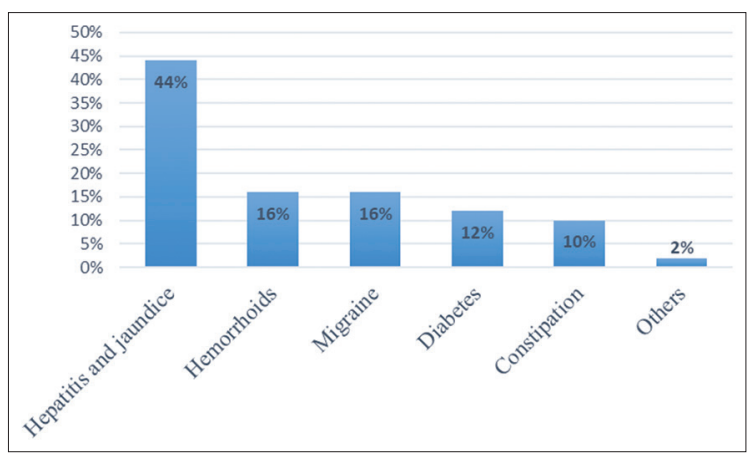

Figure 10: Different directions of the plant

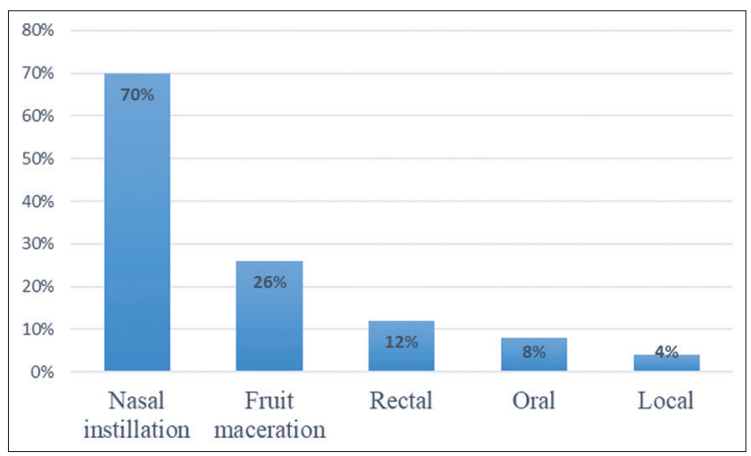

Figure 11: Route of Administration of the plant

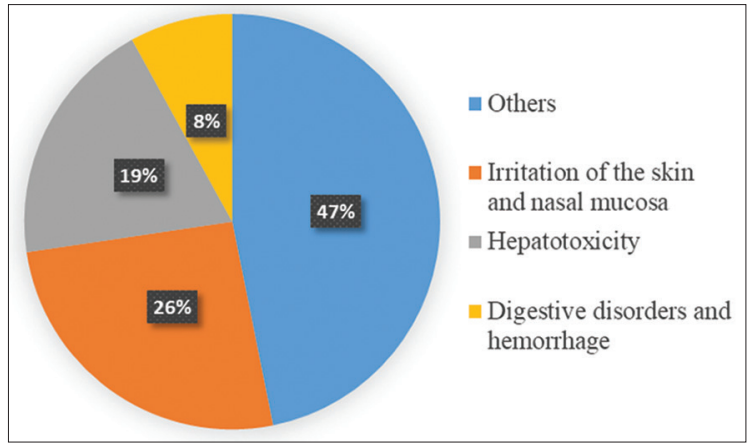

Figure 12: Different side effects
The toxicity of ass cucumber declared important by $62 \%$ of herbalists, including $19.35 \%$ say it is hepatotoxic or fatal, while $25.80 \%$ say it is toxic due to its irritant to skin and to the nasal passages. Some herbalists (four in number (04) attribute this plant other side effects such as digestive disorders (diarrhea and vomiting) and internal bleeding (Figure 12).

Kloutsos et al. [2] reported that some patients presented localized swelling of the uvula and the nasal mucosa, whereas others presented Uvula Nasal mucosa, Tongue, Cheek and Lips. Because of its harmful effects, ass cucumber is only used in adults and in children against all interviewed by herbalists. Toxic and beneficial effects of the fresh juice and elaterium have been reported including analgesic, antipyretic, and anti-inflammatory effects [10,11]. All parts of the squirting cucumber are toxic, particularly the ovoid green fruits. Several toxicity and allergic reactions have been described if used undiluted $[2,6,12,13]$. These toxic effects seem to correspond to the juice's major active compound, cucurbitacin B [7]. But the mechanism of toxicity is not well defined [14].

\section{CONCLUSION}

The ethnobotanical study carried out in the Northeast region of Algeria on Ecballium elaterium (L.) A. Rich., made it possible to highlight the use of this species in traditional phytotherapy and the possibility of toxicity from a certain dose. The survey of herbalists in the 05 cities of eastern Algeria reveals the importance of the use of the E. Elaterium fruit in local traditional medicine, it is widely used fresh $(70 \%$ of herbalists prescribe it in this form) to cure hepatitis and jaundice. (44\%). The survey of herbalists reveals in particular a black point when it comes to the medicinal use of this plant. Indeed, more than half (62\%) speak of an obvious toxicity of this plant in precise doses. Also, the survey shows the non-use of fruits in fresh form and the nonuse for children. In view of the results obtained in this study, it appears that the traditional use of E elaterium medicinal plants still persists in the eastern region of the country and this despite the ease of access to modern medication. It should be noted that the degree of toxicity of this plant remains not very well defined.

\section{REFERENCES}

1. Theophrastus. Historia Plantarium, 1st ed. Cambridge: Harvard University Press, 1916:9.9.4, 9.14.1, 9.15.6. King J, Lloyd JU, Felter H, eds. King's American Dispensatory. Cincinnati: Eclectic Medical Institute, 1998:456-458.

2. Kloutsos, G., Balatsouras, D. G., Kaberos, A. C., Kandiloros, D., Ferekidis, E., \& Economou, C. (2001). Upper airway edema resulting from use of Ecballium elaterium. The Laryngoscope, 111(9), 16521655.

3. Khalil A.M., Qaoud K.M., Toxicity and partial characterization of Ecballium elaterium fruit juice, Int. J. Pharmacogn. 31 (1993) 135-141.

4. Rust RW, Vaissiere BE, Westrich P. Pollinator biodiversity and floral resource use in Ecballium elaterium (Cucurbitaceae), a Mediterranean endemic. Apidologie 2003; 34: 29-42.

5. Uslu C, Karasen RM, Sahin F, Taysi S, Akcay F. Effect of aqueous extracts of Ecballium elaterium Rich, in the rabbit model of rhinosinusitis. Int J Pediatr Otorhinolaryngol 2006; 70(3): 515-518.

6. Raikhlin-Eisenkraft, B.Y. Bentur, Ecballium elaterium (squirting 
cucumber)-remedy or poison? J. Toxicol. Clin. Toxicol. 38(2000) 305-308.

7. Rios JL, Escandell JM. Recio MC. New insights into the bioactivity of Cucurbitacins. In: Rahamn A-Ur. (ed.) Studies in natural products chemistry: bioactive natural products (Part L). The Netherlands: Elsevier; 2005, p. 429-469.

8. Latté KP. Ecballium elaterium (L.) a rich portrait of a medicinal plant. Z Phytother 2009; 30(3): 148-154. Mazokopakis EE, Karefilakis CM, Starakis IK. The safety and efficacy of the fruit juice of Ecballium elaterium in the treatment of acute rhinosinusitis. J Altern Complement Med 2009; 15(12): 1273-1274.

9. Chan KT, Meng FY, Li Q, Ho TC, Lam TS, To Y, et al. Cucurbitacin B induces apoptosis and S phase cell cycle arrest in BEL-7402 human hepatocellular carcinoma cells and is effective via oral administration. Cancer Lett 2010; 294: 118-124.
10. Yesilada, E., S. Tanaka, E. Sezik, M. Tabata, Isolation of antiinflammatory principle from the fruit juice of Ecballium elaterium, J. Nat. Prod. 51 (1988) 504-508.

11. Agil, M.A., S. Risco, M. Miro, M.C. Navarro, M.A. Ocete, J. Jimenez, Analgesic and antipyretic effects of 'Ecballium elaterium (L.) A. Richard. Extract in rodents, Phytother. Res. 9 (1995) 135-138.

12. Kavalci C, Durukan P, Cevik Y, Özer M. Angioedema due to Ecbalium elaterium: case report. Akademik Acil Tip Dergisi 2007; 5(3): 39-40

13. Alcoceba E, Gonzalez M, Gaig P, Figuerola E, Auguet T, Olona M Edema of the uvula etiology, risk factors, diagnosis, and treatment. J Investig Allergol Clin Immunol 2010; 20(1): 80-83.

14. Adwan, G., Salameh, Y., \& Adwan, K. (2011). Effect of ethanolic extract of Ecballium elaterium against Staphylococcus aureus and Candida albicans. Asian Pacific journal of tropical biomedicine, 1(6), 456-460. 